\title{
MODELING DYNAMICS OF STORED SOIL MOISTURE AT STAGE OF CONTROL OF STRUCTURES OF AMELIORATION SYSTEMS
}

\author{
Aliaksandr Volchak ${ }^{1}$, Aleh Meshyk ${ }^{1}$, Yury Mazhayskiy ${ }^{2}$, Olga Chernikova $^{3}$ \\ ${ }^{1}$ Brest State Technical University, Belarus; ${ }^{2}$ All-Russian Research Institute of Hydrotechnics and \\ Melioration named after A.N. Kostyakova, Russia; ${ }^{3}$ Academy of Law Management of the Federal \\ Penal Service of Russia, Russia \\ volchak@tut.by, omeshyk@gmail.com, director@mntc.pro,chernikova_olga@inbox.ru
}

\begin{abstract}
The article contains the results of development of a methodology for assessing and optimizing the water regime on agricultural lands. To ensure an environmentally safe mode of humidification, operational instrumental control of dynamics of soil moisture reserves is necessary. A distinctive feature of the developed rational regime of hydro-reclamation is its inherent and appropriately justified dynamics of soil moisture reserves as a whole during the growing season and in specific phases of plant development. Methods of mathematical modeling allow us to fully and quickly present the humidity picture of the field. With this approach, it is necessary: to establish the number of experimental points in the actual boundaries of the agricultural field, required for mathematical modeling of soil moisture reserves; to determine the coordinates of the points where you should quickly measure the soil moisture and which, in turn, will be representative or characteristic, based on the most complete account of the set of properties of the field; take the optimal soil moisture for the cultivated crop and the time interval or hydro-reclamation norm, representative in general for the field; justify the representative depth of the sensor installation (sampling) in order to assess the humidity of the calculated soil profile. In the feasibility study of the support network points, using the materials of field surveys, maps of hydrozole soil moisture reserves are modeled and the statistical structure of fields of humidity of the active layer of soils in various natural hydration years. The developed method is recommended to be used for objective and qualitative assessment of the natural water regime of soils on agricultural land in the operational formation of reclamation impacts in the process of managing the structures of drainage and irrigation systems.
\end{abstract}

Keywords: soil moisture reserves, methods, modeling, reclamation rate.

\section{Introduction}

Most researchers note that the maximum yield of crops is achieved by optimizing the regime of hydro amelioration, in particular, irrigation [1;2]. Irrigation regime is a set of irrigation norms, the number, timing and duration of irrigation. There are many examples in the scientific literature when the irrigation regime focuses on some experimental field point, representative soil, or a specific agricultural crop [3; 4]. In this regard, the traditional model of the irrigation regime can be considered as a one-dimensional linear model. At the same time, the variegation of the soil cover, the stochasticity of climatic processes and conditions set a lot of uncertainties that requires creation of multifactor models that take into account the moisture balance in the soil layer [5; 6]. With any deviation of soil moisture from the optimal one, the plants suffer either from a deficiency or from excess moisture. The task we are solving is to avoid limiting the water consumption of agricultural crops by soil moisture through the continuous provision of optimal soil moisture reserves during critical periods. This will guarantee the highest intensity of photosynthesis, which, in turn, determines the maximum final biomass (yield). The main goal of the research is to develop a methodology for modeling soil moisture reserves that takes into account a set of interrelated factors, which ultimately will allow implementing of water-saving regimes of hydro amelioration. The maximum yield of crops is achieved with maximum evapotranspiration intensity, a sufficient influx of moisture to the root system and heat to the evaporating surface [7]. The lower boundary of moisture reserves is determined by the mobility of soil moisture and is approximately $60-80 \%$ of the lowest moisture capacity $\left(W_{l w}, W_{\max }\right)$ (Fig. 1, line 1). This boundary is the moisture content of rupture of water capillary bonds $\left(W_{c r w}, W_{\min }\right)$ (Fig. 1, line 2). The lowest moisture capacity $\left(W_{l w}\right)$ is the upper limit of the optimum moisture content of the root habitat soil layer (Fig. 1, line 1). Thus, the dynamics of the current soil moisture reserves $\left(W_{o j}\right)$ must meet the condition (Fig. 1, line 7 - for perennial grasses)

$$
W_{c r w} \leq W_{o j} \leq W_{l w}
$$

In this case, the crop yield, other things being equal, will be maximum. In critical phases of plant development, soil moisture $\left(W_{o j}\right)$ should be close to $\left(W_{l w}\right)$, but at certain stages of vegetation it may 
decrease to values close to $\left(W_{c r w}\right)$. The moisture content of the root layer of the soil in practice is kept in a certain average (for a given phase of crop development) range (Fig. 1, line 3), which can be defined as

$$
V_{o i}=\frac{W_{\operatorname{maxi}}+W_{\operatorname{mini}}}{2 \cdot W_{\max }} \approx \frac{W_{l w}+W_{c r w}}{2 \cdot W_{l w}} .
$$

\section{Materialsandmethods}

To control the water-air regime of soil, it is necessary to have an actual (calculated) hydrograph of soil moisture in the root layer. Since soil moisture is stochastic in nature and depends on a number of random factors, methods of mathematical statistics can be used to construct the hydrograph. The hydrograph of the natural soil moisture is most accurately calculated for the average long-term period (Fig. 1, line 4). This hydrograph can serve as a basis for modeling the dynamics of soil moisture reserves and the development of typical hydrographs of soil moisture reserves of various supplies (Fig. 1, line 5).

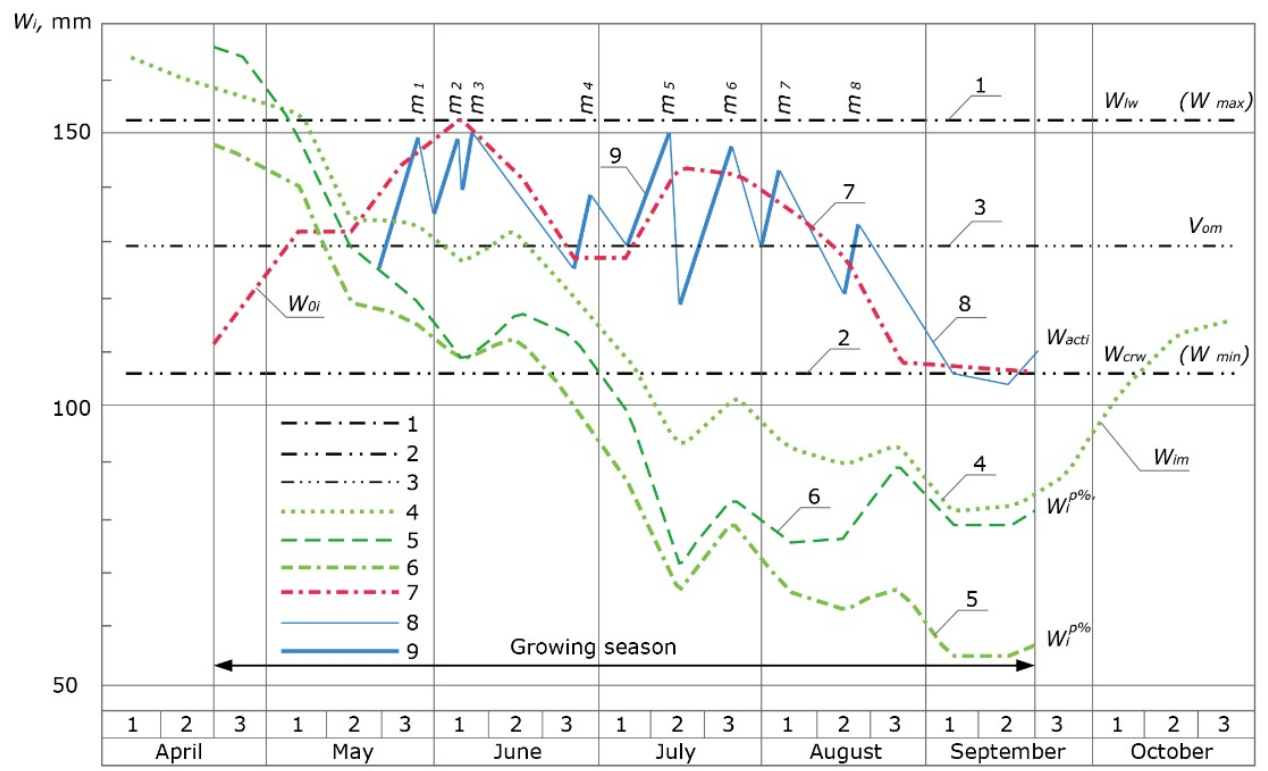

Fig. 1. Dynamics of moisture reserves in the root layer $(0.5 \mathrm{~m})$ of loamy soil: 1 - the lowest moisture capacity $\left(W_{l w}\right) ; 2$ - humidity of rupture of capillary bonds $\left(W_{c r w}\right) ; 3$ - vegetative average relative humidity $\left(V_{o m}\right) ; 4$ - long-term average $(P=50 \%)$ humidity $\left(W_{i m}\right) ; 5$ - equally provided $(P=75 \%)$ humidity $\left(W_{i}^{P \%}\right) ; 6$ - humidity adjusted according to the calculated year $\left(W_{i}^{P \%}\right)$; 7 - humidity of optimum level set for perennial grasses $\left(W_{o j}\right) ; 8$ - actual soil moisture $\left(W_{a c t i}\right)$; 9 - irrigation rate $(m), \mathrm{mm}$

At present, various models that describe the dynamics of soil moisture reserves with varying degrees of discreteness and accuracy are proposed $[8,9,10]$ etc., but the water balance methodis most acceptable for practical purposes

$$
W_{e i}=W_{b i}+X_{i}-E_{o i}-Y_{i}+G_{i}-J_{i},
$$

where $W_{e i}, W_{b i}-$ moisture reserves, respectively, at the end and beginning of the estimated time interval ( $i$ - month, decade, day), mm;

$X_{i}$ - amount of precipitation for the estimated time interval, $\mathrm{mm}$;

$E_{o i}-$ optimal crop water consumption, mm;

$Y_{i}$ - surfacerunoff, mm;

$G_{i}$ - soil component of the water balance of the calculated soil layer, $\mathrm{mm}$;

$J_{i}$ - infiltration of soil moisture into deeper layers from the aeration zone, $\mathrm{mm}$.

As a rule, equation (3) is used with some assumptions: the surface runoff value $\left(Y_{i}\right)$ is not taken into account, since for average perennial conditions during the growing season, surface runoff is rather 
rare; infiltration $\left(J_{i}\right)$ is also not taken into account. Otherwise, these consumable items $(\Delta)$ will totally be estimated as

$$
\Delta=\left(Y_{i}+J_{i}\right)=W_{f w}-W_{e i} \text {, if } W_{e i} \geq W_{l w}
$$

where $W_{f w}-$ total moisture capacity of the calculated soil layer, $\mathrm{mm}$.

\section{Results and discussion}

The research shows that the probability distribution of the soil moisture values obeys the normal law and is determined by two parameters (average long-term value - $W_{i m}$; coefficient of variation $\left.C_{v i}\right)$, and the provided values of moisture reserves $\left(W_{i}^{P \%}\right)$ can be calculated according to the scheme

$$
W_{i}^{P \%}=W_{i m} \cdot\left(C_{v i} \cdot F_{P \%}+1\right),
$$

where $F_{P \%}$ - normalized deviations of the ordinates of the estimated frequency curve from the long-term average value.

The research has shown that the coefficient of variation $\left(C_{v i}\right)$ can be fairly accurately determined by the dependence [11]

$$
C_{v i}=\lambda \cdot\left(\frac{W_{l w}}{W_{i m}}+\frac{W_{l w}}{W_{f w}}\right),
$$

where $\lambda$-empirical coefficient depending on the moisture capacity of the soil and its natural moisture.

Moreover, the quantity $(\lambda)$ is defined as

$$
\lambda=A \cdot W_{l w}+B
$$

where $A, B$-empirical coefficients depending on the thickness of the calculated soil layer (for 0.5 - meter layer, respectively, are $0.0021 ; 0.11$ ).

When determining the moisture content of the root layer of the soil during the growing season in characteristic years, it is necessary to take into account the asynchrony of the calculated (Fig. 1, line 5) provided values of soil moisture reserves $\left(W_{i}^{P \%}\right)$ with their actual course in the year of the same frequency $\left(W_{i}^{P \%}\right)$ (Fig. 1, line 6). The measure of asynchrony is determined by the inadequacy of the ratios of the natural resources of heat and moisture at specific calculated time intervals and in general during the vegetation period of plants. Therefore, the soil moisture $\left(W_{i}^{P \%}\right)$, obtained for characteristic years according to equation (5), requires adjustment taking into account its real course in the similar real year of estimated frequency $\left(W_{i}^{P \%}\right)$. Schematizing the intra-annual distribution of the revealed discrepancies, it is necessary to proceed from the presence of critical periods (phases) of crop development, in which they are most sensitive to fluctuations in soil moisture reserves. The adjusted values of soil moisture $\left(W_{i}^{P} \%\right.$ ' $)$ of any frequency are estimated by the formula

$$
W_{i}^{P \%^{\prime}}=W_{i}^{P \%}-\frac{\sum_{i=1}^{n} W_{i}^{P \%} \cdot\left(1-\alpha_{W}(P)\right) \cdot\left(K_{b \max }^{P \%}-K_{b i}^{P \%}\right)}{\sum_{i=1}^{n}\left(K_{b \max }^{P \%}-K_{b i}^{P \%}\right)},
$$

where $K_{b \max }^{P \%}$ - maximum ten-day value of the coefficient of water consumption (biological, bioclimatic, etc.) of $P \%$ - frequency;

$K_{b i}^{P}$-value of the coefficient of water consumption of the same frequency;

$\alpha_{W}(P)$ - coefficient of transition from soil moisture values $\left(W_{i}^{P \%}\right)$ to its adjusted values $\left(W_{i}^{P \% \prime}\right)$.

The analysis of the asynchrony of the moisture content of soil moisture reserves in the adjacent averaging intervals revealed an empirical dependence for determining the transition coefficient $\left(\alpha_{W}(P)\right)$. 


$$
\alpha_{w}(P)=\left(\left(0.915 \cdot \exp \left(\frac{26}{W_{l w}}\right)\right)-\alpha_{t} \cdot \exp \left(\frac{\beta_{t}}{W_{l w}}\right) \cdot P\right)^{-1},
$$

where $\alpha_{t}$ and $\beta_{t}$-empirical coefficients depending on the duration of the growing season - for May-August $\left(\alpha_{t}^{V-V I I I}=0.047, \beta_{t}^{V-V I I I}=202\right)$, for April-October $\left(\alpha_{t}^{I V-X}=0.084, \beta_{t}^{I V-X=} 152\right)$.

Thus, it is possible to obtain a calculated hydrograph of the moisture reserves of the root layer of the soil of any frequency, taking into account the biological characteristics of the cultivated crop. The resulting hydrograph can be used as a strategic component of management of regimes of soil moisture reserves at the design and operation of hydro-reclamation systems, while managing linear and network structures. At the same time, various types of hydro-reclamation regimes (humidification, humidification-flushing, irrigation-possible, economically-possible), which can be supplemented with technically-possible and environmentally-necessary ones, are implemented. In case of proper economic justification, the developed operational regime ofhydro-reclamation can be called "rational" [11]. The rational regime of hydro-reclamations corresponds to the justified dynamics of soil moisture reserves both in general during the growing season and in specific phases of plant development ( $\left.W_{\text {acti }}\right)$ (Fig. 1, line 8).

The presence of deficits $\left(D_{i}\right)$ or excesses $\left(U_{i}\right)$ of the water balance $(W B)$ of the root layer of the soil for the estimated time interval can be determined from the ratios

$$
D_{i} \cdot\left(H_{i}\right) W B=\left\{\begin{array}{l}
W_{i}-W_{l w}, i f W_{i}>W_{l w}-\text { drainage is required; } \\
0, \text { if } W_{l w} \geq W_{i} \geq W_{c r w}-\text { hydro }- \text { reclamations are not required; } \\
W_{i}-W_{c r w}, \text { if } W_{i}<W_{c r w}-\text { irrigation is required. }
\end{array}\right.
$$

In developing the regimes of hydro-reclamations, the water management problem is reduced to describing the natural intra-annual course of soil moisture reserves in the root layer $\left(W_{i}^{P \% \prime}\right)$ (Fig. 1, line 6), modeling the intra-annual course of soil moisture values $\left(W_{a c t i}\right)$ (Fig. 1, line 8 ) with the establishment, at the same time, of the inevitable imbalances $\left( \pm m_{i P} \%\right)$ and the ways of eliminating them by combining curves 6 and 7 in one line (Fig. 1, lines 8-9).

Decade values of deficits (excesses) of the water balance of the root layer of the soil $\left( \pm m_{i P} \%\right)$ are found from the ratio

$$
\pm m_{i P \%}=W_{i}^{P \%{ }^{\prime}}-W_{o i}
$$

where $W_{i}^{P \% \prime}$ - actual soil moisture, and under conditions of irrigation and drainage this value should not fall below the lower optimal level, that is $W_{i}^{P \%} \geq W_{c r w}, W_{\text {min }}$;

$W_{o i}$ - optimally needed soil moisture reserves, providing optimal crop water consumption.

The soil moisture reserves of the required optimality level $\left(W_{o i}\right)$ (Fig. 1, line 7) are determined by the corresponding percentage of frequency that is rational for this regime of hydro-reclamations $\left(W_{o i}=W_{a c t i}\right)$. Then formula (11) takes the following form

$$
\pm m_{i p \%}=W_{i}^{P \%}-W_{a c t i}
$$

where $W_{a c t i}$ - rational value of soil moisture (corresponding to the frequency) for this type of hydro-reclamation regime.

At the same time, the problem of the most complete copying by the line $\left(W_{\text {acti }}\right)($ Fig. 1, line 8$)$ of the course of soil moisture reserves of a given level of optimality corresponding to the optimal water consumption $\left(W_{o i}\right)$ (Fig. 1, line 7) is being solved. This is carried out by amelioration influences $\left(m_{i}\right)$ (Fig. 1, line 9) in terms coinciding with the time of significant differences between curve 7 and line 8 (Fig. 1). When the water regime of soil is regulated by the amelioration norm $\left(m_{i}\right)$ (Fig. 1, line 9) in combination with natural soil moisture reserves $\left(W_{i}^{P \%}\right)$, a rational dynamics of soil moisture $\left(W_{a c t i}\right)$ is being formed. The tendency of changes in natural soil moisture reserves $\left(W_{i}^{P \% \prime}\right)$ should be taken into account when modeling their rational course in the inter-irrigation period $\left(W_{a c t i}{ }^{e}\right)$.

$$
W_{a c t i}^{e}=\frac{W_{a c t i}^{b} \cdot\left(2 \cdot W_{e i}^{P \%^{\prime}}-X_{i}\right)+X_{i} \cdot\left(W_{b i}^{P \%^{\prime}}+W_{e i}^{P \rho^{\prime}}\right)}{2 \cdot W_{b i}^{P \%^{\prime}}+X_{i}},
$$


where $W_{a c t i}^{b}$ - soil moisture at the beginning of the base period or formed as a result of watering (Fig. 1, line 8);

$W_{a c t i}{ }^{e}-$ soil moisture at the end of the base period or the first time interval after watering (Fig. 1, line 8);

$W_{b i}^{P}{ }^{P}$ and $W_{e i}^{P \%}$ - actual soil moisture, respectively, at the beginning and end of the base period (Fig. 1, line 6);

$X_{i}$ - projected precipitation for the corresponding base period.

Irrigation rates $\left(m_{i}\right)$ are obtained graphically as a result of optimization of soil moisture reserves $\left(W_{\text {acti }}\right)$ (Fig. 1, lines 8-9). The projection of the inclined line 9 onto the abscissa of time depends on the area of the irrigated field, irrigation rate, irrigation method, soil absorption capacity and the rain intensity of the sprinkling devices used. Assessment of the environmental consequences of watering is carried out using the following algorithm [12]

$$
U=\sum_{i=1}^{n}\left\{\begin{array}{c}
k_{1}(m) \cdot\left[W_{a c t i}-W_{\max }\right], \text { if } W_{a c t i}>W_{\max } \\
0, \text { if } W_{\min } \leq W_{a c t i} \leq W_{\max } \\
k_{2}(W) \cdot\left[W_{\min }-W_{a c t i}\right], \text { if } W_{a c t i}<W_{\min }
\end{array}\right.
$$

where $U$ - damage from waterlogging of the soil during watering (erosion, loss of irrigation water, etc.), as well as from its excessive drying before watering (crop shortage, reduced irrigation efficiency, etc.);

$k_{1}(m), k_{2}(W)$-damage indicators corresponding to excess/deficiency of soil moisture reserves.

It is known that the agricultural field in terms of its complex of properties (relief, microrelief, soil cover, geological conditions, nature and density of plants, natural water and mineral nutrition, etc.), as a rule, is extremely heterogeneous. To ensure an environmentally safe irrigation regime, operational instrumental monitoring of the dynamics of soil moisture reserves is necessary. However, it is very difficult to realize this task at low cost, taking into account the actual variegation of field properties. Quickly and fairly fully presentation of the moisture picture of the agricultural field is only possible using field research materials in conjunction with mathematical modeling methods.In case of this approach, it is necessary: to establish the number of test points in the actual boundaries of the agricultural field that is required for mathematical modeling of soil moisture reserves; to determine the coordinates of the points at which soil moisture should be quickly measured, which will be representative; to adopt the optimum soil moisture or hydro-reclamation rate (irrigation, drainage rate) for cultivated crops and the time interval; to justify the representative depth of soil moisture sensors. We assume that soil moisture is a random variable, and its possible values are distributed continuously in the studied area. The probability of an event $(P)$ of one or another random variable $(W)$ is less than some current variable $(w)$, however, their general properties can be characterized by the distribution function of a random variable $(W)$

$$
F(W)=P(W<w)
$$

The function $-(F(W))$ is an integral characteristic of the distribution of random values of soilhydrological constants or actual soil moisture within the field. The derivative of the function $(F(W))$ is called the density of its distribution - $(f(W))$. The probability of a random variable $(W)$ falling into a certain interval $[a, b]$ is defined as

$$
P(a<W<b)=\int_{a}^{b}(W) d W
$$

For a genetically homogeneous population, the random variable $(W)$ often obeys the normal probability distribution law, in which the distribution density $(f(W))$, the distribution function $(F(W))$ and the normalized deviations $(t)$ are found from the formula [13]:

$$
\begin{gathered}
f(W)=(2 \pi)^{-0.5} \exp \left(-t^{2} / 2\right) ; \\
F(W)=(2 \pi)^{-0.5} \int_{\infty}^{t} \exp \left(-t^{2} / 2\right) d t ;
\end{gathered}
$$




$$
t=(W-w)^{2} / \delta^{2} .
$$

The mathematical expectation $(O)$,dispersion $\left(\delta^{2}\right)$ and mean-square deviation $(S)$ are calculated by standard methods.

Soil moisture $\left(W_{h i}\right)$ for the field, in general, is an infinite population. In the process of field research, the task should be to obtain a sample population that has the completeness of all the properties of the general population. The central limit theorem is applicable to the selective method, this theorem is written in the form [13]

$$
P=\left[(\bar{W}-\bar{w})<t \delta n^{-0.5}\right]=F(t)=(2 \pi)^{-0.5} \int_{\infty}^{t} \exp \left(-t^{2} / 2\right) d t,
$$

where $n$-number of definitions (sample volume).

It follows from the theorem that for $(n \rightarrow \infty)$ the probability of the difference $(W-\bar{w})$ within the limits of $\left( \pm t \delta n^{-0.5}\right)$ is equal to $(F(t))$. Random sampling is as follows. The entire ameliorated area is divided into squares that are fully included in the accepted boundaries of each field. During the mathematical interpretation of this operation, instead of the probability space $\{\Omega, F, P\}$, we consider its finite subspace $\{\Omega, F, P\}$ with a set of elementary events $\left(W_{i}\right)$

$$
\bar{\Omega}=\left\{W_{1}, W_{2}, \ldots, W_{i}, \ldots, W_{l}\right\},
$$

where $\Omega$-random sample of moisture, i $=1,2, \ldots, l$;

$i$ - number of the square;

$l$ - number of squares;

$W_{i}$ - soil moisture value determined in the center of the corresponding square.

The numerical function of an elementary event $(W)$ is represented as a random variable

$$
F(W=f(W)) \text {. }
$$

When implementing this approach, it is believed that the value of a specific soil - hydrological constant $\left(W_{j h i}\right)$ or soil moisture $\left(W_{h i}\right)$ is constant within each square. The number of squares $(l)$ is taken depending on the nature of the field and the crop grown. The sample volume is assigned taking into account the economic factor. This follows from the limit central theorem. The representativeness of the sample increases with increasing the number of samples, which, in turn, increases the cost of experimental work. In case of random sampling, the sample volume can be set by the formula

$$
n=t^{2} \delta^{2}(\bar{W}-\bar{w})^{-2} .
$$

The accuracy of determining the average moisture of an agricultural field increases the probability of achieving a programmed crop on a specific plot of land. Practice shows that the estimated crop yields, based on the reserves of productive moisture and water consumption coefficients for soil differences and within them, fluctuate significantly. It is also known that when prescribing irrigation rates with a relative mistake( $> \pm 10 \%$ ), the yield of most crops is significantly reduced. During the feasibility study of the network of observation points, the hydroisopleth maps of soil moisture reserves are built and statistical structures of moisture fields of the root layer of soil are modeled in different years of natural moisture. In a joint analysis of the hydroisopleth maps of soil-hydrological constants and the structure of soil moisture fields in different periods, the location of reference points, at which the soil layer moisture is quantitatively equal to its average value within the boundaries of each agricultural field, is established. These points are grouped along the hydroisopleth, close to the weighted average value of one of the main soil-hydrological constants - the lowest soil moisture capacity $\left(W_{l w}\right)$ of the particular agricultural field.

The developed methodology and the abovementioned algorithm were tested on a number of agricultural crops grown in Belarus: perennial herbs, vegetables and grains. The main parameters of irrigation regimes were compared with the biologically optimal water regimes of these crops. The obtained values of irrigation norms up to $150-200 \mathrm{~m}^{3} \cdot \mathrm{ha}^{-1}$ (during the growing season) are lower in comparison with the norms established by traditional methods. The fundamental difference of the research results lies in the used methodology of theoretical estimates and the particularities of the methods of formation of the main components of the amelioration regime (irrigation and watering 
rates, average dates and periods of irrigation, inter-irrigation periods). It is important that the process of forming the anthropogenic water regime of soil is flexible, initially controllable, takes place in a dialogue mode with a comprehensive consideration of the influence of limiting factors and, as a result, makes it possible to save irrigation water and reduce economic costs.

\section{Conclusions}

The stated approach is recommended to be used for objective and qualitative assessment of the natural water regime of soil on agricultural lands during the operational formation of amelioration impacts in the process of managing the construction of complex irrigation systems.

\section{References}

[1] Papastylianou P.T., Argyrokastritis I.G. Effect of limited drip irrigation regime on yield, yield components, and fiber quality of cotton under Mediterranean conditions. Agricultural Water Management, Elsevier, vol. 142(C), 2014, pp. 127-134.

[2] Likhatsevich A.P., Latushkina G.V., Romanov I.A. Management of crop irrigation regime in Belarus. JournalLand reclamation,2019. No 2(88), pp. 18-25. (In Russian).

[3] Oweis T.Y., Farahani H.J., HachumA.Y. Evapotranspiration and water use of full and deficit irrigated cotton in the Mediterranean environment in northern Syria. Agricultural Water Management, Elsevier, vol. 98, issue 8, 2011, pp. 1239-1248.

[4] Hamoud Y.A., Guo X., Wang Z., Shaghaleh H., Chen S., Hassan A., Bakour A. Effects of irrigation regime and soil clay content and their interaction on the biological yield, nitrogen uptake and nitrogen-use efficiency of rice grown in southern China. Agricultural Water Management, Elsevier, vol. 213, 2019, pp. 934-946.

[5] Li Y.P., Huang G.H., Nie S.L., Chen X. A robust modeling approach for regional water management under multiple uncertainties. Agricultural Water Management, Elsevier, vol. 98, issue 10, 2011, pp. 1577-1588.

[6] Byrne Colin F., Stormont John C., Stone Mark C., 2017. Soil water balance dynamics on reclaimed mine land in the southwestern United States. Journal of Arid Environments, Elsevier, vol. 136, pp. 28-37.

[7] Allen R.G., Pereir L.S., Raes D., and Smith M. Crop Evapotranspiration. Guidelines for Computing Crop Water Requirements. - FAO Irrigation and Drainage Paper, No 56, FAO, Rome, Italy, 1998, $300 \mathrm{p}$.

[8] Senay G., Verdin J.P., Lietzow R., and Melesse A. Global Daily Reference Evapotranspiration Modeling and Evaluation. - JAWRA Journal of the American Water Resources Association, vol. 44, issue 4, 2008, pp. 969-979, doi: 10.1111/j.1752-1688.2008.00195.x.

[9] Roderick M.L., Hobbins M.T. and Farquhar G.D. Pan Evaporation Trends and the Terrestrial Water Balance. II. Energy Balance and Interpretation. - Hydrology and Water Resourses, vol. 4, 2009. doi: 10.1111/j.1749-8198.2008.00214.x.

[10] Xingyao P., Lu Z., Nicholas J.P., Jun X., Yongqiang Z. Probabilistic modeling of soil moisture dynamics of irrigated cropland in the north China plain. Hydrological Sciences Journal/journal Des Sciences Hydrologiques 56, 2011, pp. 123-137.

[11] Valuev V.E., Volchek A.A., Meshik O.P. Modeling the dynamics of soil moisture reserves at the stage of managing the construction of amelioration systems. Bulletin of the Brest Polytechnic Institute. Water construction, heat power engineering, ecology, 2000, No 2, pp. 30-35. (In Russian).

[12] Likhatsevich A.P. The ways to improve the efficiency and environmental safety of sprinkling. Ecological aspects of amelioration. Collection of scientific papers. Minsk, 1990, pp. 34-42. (In Russian).

[13] Wentzel E.S. Probability theory. Moscow, Academy, 2005.576 p. (In Russian). 